\title{
Zeitgeschichtliche Impressionen zur Politischen Kultur in Deutschland
}

\author{
Oberreuter, Heinrich: Wendezeiten. Zeitgeschichte als Prägekraft politischer Kultur, Olzog Ver- \\ lag, München 2010, 384 Seiten, € 29,90.
}

Heinrich Oberreuter berichtet in diesem Band über „Wege durch ein Jahrhundert“ von der Diktatur zur Demokratie (S. 11). Den im Haupttitel enthaltenen Begriff „Wendezeiten“ weist er bereits im ersten Satz als unzutreffend zurück: „Wendezeiten? Im Grund vermag dieser Begriff die zeitgeschichtlichen Umbrüche eines knappen Jahrhunderts nicht wirklich zu fassen“ (S. 11). Was stattdessen den Band leitet und was sein Anliegen ist, lässt der Untertitel „Zeitgeschichte als Prägekraft politischer Kultur“ vermuten; konkret formuliert wird es nicht. Erst viel später bespricht der Autor, was politische Kultur ist: „das Geflecht politisch relevanter Einstellungen und Werthaltungen“, „die Interdependenz zwischen diesen Einstellungen und dem politischen System samt seinen institutionellen Ausprägungen “ sowie „die historische Herkunft, den gegenwärtigen Zustand und den zukunftsbezogenen Wandel" von Einstellungen und Institutionen (S. 314).

In Oberreuters Definition der politischen Kultur ist die Zeitgeschichte demnach bereits als konstitutives Merkmal enthalten; die Kausalbeziehung zwischen beiden bleibt ungeklärt. In der Einleitung schreibt er: „Hindernisse, Verspätungen, Irr- und abgründige Abwege unterlagen historischen, politisch-kulturellen Prägungen: Ohne geschichtliche Erfahrungen sind aktuelle politisch relevante Einstellungen und Wertorientierungen und ihr Wandel nicht denkbar. (...) Dass politische Kultur sich in historischen Prozessen gestaltet und entfaltet, wird selten hervorgehoben. (...) Die Zeitumstände wirkten auf sie ein, ebenso wie sie selbst Zeitumstände (bis hin zu Gestalt und Interpretation politischer Systeme) zulässt und fördert." (S. 12)

Die unklare Fragestellung und der uneindeutige theoretische Zugriff auf das Thema werden im Nachwort am Ende des Bandes aufgeklärt: Er wurde nicht als Gesamtwerk konzipiert, sondern enthält Publikationen verschiedener Zeiten. Oberreuter: „Es geht hier kaum um einen Beitrag zur Forschung, sondern um Interpretation und Erklärung von historischen Bestimmungsfaktoren politisch-kultureller Entwicklungsschritte während eines zerrissenen, am Ende aber doch eher versöhnlichen Jahrhunderts zwischen Autoritarismus, Diktatur und Demokratie.“ Sie seien alle „aus der Sicht wertgebundener pluralistischer Demokratie, ihrer Gefährdung und ihrer Erringung“ geschrieben „und durch diese Perspektive zusammengehalten“ (S. 347).

Oberreuters breites Verständnis politischer Kultur weicht vom sonst üblichen Zugriff ab, diese auf die Denk- und Verhaltensweisen der Bürger inklusive Meinungen, Einstellungen und Werten zu begrenzen. Diesem Zugriff wirft er vor, den historisch-genetischen Aspekt auszublenden (S. 12). Das Ergebnis dieser Herangehensweise, schon begrifflich nicht zu separieren, ist indes ein „Alles ist mit allem verbunden“. So erklärt Oberreuter unter Verweis auf Jacques LeGoff, Geschichte bedürfe der Vergegenwärtigung und sei „weithin ein (Interpretations-),Konstrukt““. Gleichzeitig nimmt er an, historische Erinnerung sei „ohne Zweifel“ „neben Sprache, Kultur und Religion ein wichtiges Element nationaler Identitätsbildung“. Wie ist denn nun aber das Verhältnis aus aktiver Konstruktion und passivem Geprägtsein? Von welchen Rahmenbedingungen hängt es möglicherweise ab? Der Zusammenhang wird nicht systematisch untersucht und auch nicht hinterfragt. Stattdessen geht Oberreuter davon aus, dass „Geschichtserkenntnis“ „durch kontingente Faktoren wie 
Subjektivismen und Parteilichkeiten kontaminiert“ werden könne (S. 21). Hier wird also einerseits plötzlich doch die Möglichkeit „objektiver“ Geschichtserkenntnis angenommen, andererseits werden wiederum diffus gefasste Nebeneinflüsse („Subjektivismen“, „Parteilichkeiten") aufgrund der Kontingenzannahme der systematischen Prüfung entzogen. Erstaunlich ist auch der weitgehende Verzicht darauf, konkrete Akteure zu nennen und gleichzeitig Phänomene oder Strukturen zu Subjekten zu machen, zum Beispiel: „Die Diktaturen des 20. Jahrhunderts“ haben ihre „Wirkungschancen genutzt“ (S. 12), „Der bewundernswerte Herbst 1989 vermochte (...) nicht, jahrzehntelange Prägungen auszulöschen“ (S. 57), „Diese Verfassung (...) dachte nicht daran, diese Prinzipien zu schützen“ (S. 91) oder „ein versöhnliches Jahrhundert“ (S. 347).

Oberreuter streift viele für die Politikwissenschaft wichtige Themen der jüngeren deutschen Geschichte: das Verhältnis zwischen Bürgern und Staat, die Verfassungspolitik, die Weimarer Republik, die NS-Diktatur, den Neubeginn der "geglückten Demokratie“ (unter Bezug auf Edgar Wolfrum) der Bundesrepublik Deutschland, die Systemgegensätze während des Kalten Krieges, die deutsche Einheit. Dabei greift er auf umfassende Sekundärquellen vor allem von Zeithistorikern und Staatsrechtlern zurück. Dennoch: Aufgrund der inkonsistenten Entstehung der einzelnen Kapitel, des breiten Verständnisses der politischen Kultur, des Verzichtes auf einen durchgehenden klaren Analyseansatz bleiben die Erkenntnisse für das Fachpublikum gering, und die stete Bemühung eines „wertgebundenen“ (Oberreuter) Deutungszugriffes, der zentrale Behauptungen oft ohne nähere Begründung als erwiesen hinstellt, treibt die Debatte nicht inhaltlich voran: Die „Deutschen im Osten haben sich ihre Verwirklichung mutig und gewaltlos erkämpft“ (S. 18), „Gewiss verfügen Ost und West nun gemeinsam über das bessere Modell“ (S. 58), „Nicht nur aus Feigheit und zögerlichem Opportunismus blieb die Widerstandsbewegung in Deutschland (...) schwach“ (S. 172), „Politische Dämme gebaut und politisch gehandelt haben [im Gegensatz zu den 68ern] liberal-konservative Intellektuelle. Den gesellschaftlichen Wertwandel konnten sie weder aufhalten noch wollten sie es in seinen als positiv empfundenen Dimensionen" (S. 269). Oberreuters Sicht auf die Bundesrepublik Deutschland scheint die einer Republik, die „angekommen“ ist, doch diese Diagnose vom „Ende der Geschichte“ wird nicht jeder Leser teilen.

Interessanter sind die Beiträge dort, wo sie sich mit konkreten Fragestellungen befassen, zum Beispiel der Entwicklung der deutschen Parteien oder dem Verfall des Weimarer Verfassungssystems. Auch hier gehen sie jedoch kaum über die einschlägigen Studien hinaus.

Fazit: ein Buch zum Durchblättern für den Vergleich politischer Interpretationen deutscher Zeitgeschichte - genau das, was der Autor (siehe Nachwort) anstrebte. Was neue Erklärungen dieser Prozesse angeht, so ist sein Beitrag begrenzt. 